\title{
Practice-Based Literary Research as Activated Inquiry
}

\author{
Vincent Broqua
}

\begin{abstract}
:
Literary artistic practice should analyse and describe its modes and modalities. Based on the study of Caroline Bergvall's and Jena Osman's practice-based research, this article focuses on inquiry as one of the modes of literary research, while also showing the use of introducing poetry within the discourse of literary research. The two works investigated activate their research by the creation of a poeisis of inquiry. This investigation allows for a renewed consideration of artistic research.
\end{abstract}

\section{Introduction}

In the text of her inaugural lecture to the Chair of Practice and Theory of Research in the Visual Arts at Leiden University, Janneke Wesseling defines artistic research as "the critical and theoretically positioned reflection by the artist on her practice in the world, in artworks, and in the written text." Whether or not this definition obtains for visual arts, it is both apt and problematic for what one might call literary artistic research or literary research. Since the medium of literature is precisely words and 'text' (in the broad sense of the term, be it on- or off-the-page writing), the distinction between non-verbal artworks and written text cannot be applied here. However, Wesseling's definition gains in precision when she moves on to a second distinction, namely the one between discursive and non-discursive: "The reflection finds expression in the interconnection of artwork and discursive writing." 2 What might this entail for literary research, when literary research does not so much come in the form of discursive writing, but in the form of criticism and poetics, which in themselves rely on a "critical and theoretically positioned reflection" ${ }^{3}$ such as Wesseling demands?

1 Janneke Wesseling, Of Sponge, Stone and the Intertwinement with the Here and Now: A Methodology of Artistic Research. Amsterdam: Valiz, 2016, pp. 9-10.

2 Wesseling (2016), Of Sponge, p. 10.

3 Ibid. 
The texts collected in a volume I co-edited in 2012, Formes critiques contemporaines, show that the definitions and modes of practice-based criticism are manifold. ${ }^{4}$ Nevertheless, a general definition of practice-based criticism could entail a critical investigation using some of the modes and methods of research (a given question or topic, a hypothesis, an argument, sometimes a demonstration ...) while broadening the range of the methods and writing-styles of orthodox criticism and literary history. For sure, it is problematic to assume that criticism and academic writing have or should have a fixed and conventional form, as Roland Barthes's articles and books, among others, perfectly demonstrated a long time ago. Yet practice-based criticism further broadens and enriches such forms, as it emerges from practical or creative activities such as translation, editing, documenting, interviewing. ${ }^{5}$

The forms and modalities of literary artistic research are not only to be sought for in the field of criticism, however. In what follows, I want to explore some of the characteristics of practice-based literary research with precise examples taken in the poetic anglophone and francophone domains. Poetry is often bracketed out of the discourse around artistic research, assuming that only fiction and narrative are possible candidates for literary research. Since literary research must factor in discursive modes, and since poetry, in some of its forms, goes against speech and discourse, it is often assumed that poetry is ill-suited to reach a satisfying definition of literary research. I will try to show the contrary.

Through my examples, and notably Caroline Bergvall's "Say: Parsley" 6 and Jena Osman's Public Figures, ${ }^{7}$ I will outline some of the defining features of what practice-based literary research might be, and particularly how it activates research via poiesis. Meanwhile, I will take the opportunity to think about some of the reasons why the common definitions of artistic research, such as Wesseling's, might not fully apply to literary artistic research. If the field, therefore, needs to define itself further, this should be attempted without abiding

4 This was a special issue of Formes poétiques contemporaines 9 (2012), Vincent Broqua/ Jean-Jacques Poucel, eds. It presented $5^{2}$ contributions by critics, authors, publishers, and translators who explore new critical modes.

5 Other than the contributions in Formes poétiques contemporaines 9 (2012) see also Antoine Berman, L'épreuve de l'étranger. Paris: Éditions Gallimard, 1984, for translation as criticism; and for interviews and artistic research see Norman K. Denzin, "The Reflexive Interview and a Performative Social Science," in: Qualitative Research 1:1 (2001), pp. 23-46. Denzin's argument and examples are extremely valuable, although his notion of a "moral community" (p. 24) as well as the periodisation he developed (cf. p. 25) are open to question.

6 Caroline Bergvall, "Say: Parsley," in: Fig. Cambridge: Salt Publishing, 2005, pp. 49-6o.

7 Jena Osman, Public Figures. Middletown, CT: Wesleyan University Press, 2012. 
by the rules of reifying political injunctions that make artistic research the new commodity of academic discourse. As Wesseling says:

As we all know, the political pressure on artists and academics to deliver concrete 'results' is enormous. Artists are increasingly expected to create and produce 'deliverables' and to be able to demonstrate the social usefulness and commercial value of their 'products' .... I believe we should therefore avoid the term 'knowledge production' in relation to artistic research. 'Knowledge production' belongs to a neoliberal jargon, along with terms like innovation, applicability and valorization. ${ }^{8}$

\section{Practice-Based Literary Research as Inquiry}

Just like any form of practice-based art, practice-based literary research investigates; it is a form of practice-based inquiry. In her book of essays called The Language of Inquiry, the US poet Lyn Hejinian argues that "the language of poetry is a language of inquiry, not the language of a genre." She states that poetics is "a pragmatic realm," since "the reasons and reasonings that motivate poet (and poem) are embedded in the world and in the language with which we bring it into view. The resulting praxis is addressed to phenomenological and epistemological concerns."10 Defined in such a way it could be assumed that all poetry is criticism and that all poetry is thus a mode of inquiry close to the investigations and experiments fundamental to literary research. However, Hejinian makes two neat distinctions that allow complexifying matters further. First, she demonstrates that the knowledge gained "is not knowledge in the strictest sense; it is, rather, acknowledgement-and that constitutes a sort of unknowing."11 Second, she adds that although poetry is to know that things are, "to know that things are is not to know what things are."12

In developments in contemporary poetry since the publication of her book, many younger poets have sought to connect the that and the what of poetic practice. Indeed, one of the defining features of our contemporary moment in the visual arts as well as in writing is a resort to the mode and the methods

\footnotetext{
8 Wesseling (2016), Of Sponge, p. 34.

9 Lyn Hejinian, The Language of Inquiry. Los Angeles, CA: The University of California Press, 2000, p. 3 .

10 Hejinian (2000), Language, p. 2.

11 Ibid.

12 Ibid.
} 
of inquiry. And although the artists and writers working in such ways may not refer to practice-based research and even less so to artistic research, their work qualifies as artistic research and is even positioned as research. In the field of visual arts, Laura Poitras's Astro Noise in 2016 at the Whitney or Kader Attia's installation Réfléchir la mémoire at the Centre Pompidou for the Marcel Duchamp Prize (2016) come to mind. ${ }^{13}$ To name a few poets, Franck Leibovici's recent Bogoro (2016, with Julien Seroussi) is a conceptual exploration of one of the trials of the International Court of Justice, ${ }^{14}$ while Claudia Rankine's Citizen (2014) explores racial prejudices in the United States of America. ${ }^{15}$ Jennifer Scappertone's project "The Data that We Breathe," developed in 2016 with Caroline Bergvall and Judd Morrissey at the Richard and Mary L. Gray Center for Arts and Inquiry, was accompanied by a course on the poetics and politics of air. ${ }^{16}$ My book Récupérer (2015) ${ }^{17}$ has a section called "enquêtes" (inquiries) and is about inquiries in the unchartered field of the diverse or miscellaneousness, with Marcel Mauss's essay on the techniques of the body as a starting point and a foil. ${ }^{18}$ Such practices can be serious and funny, and they can even come with a slightly absurd twist, as in the case of Lisa Robertson. A serious researcher (see her book on architecture ${ }^{19}$ ) as well as a poet, the Canadian poet recently published her experiments and research on how the world is viewed through pink glasses. This was an attempt at questioning what it means to write the experience of the world by submitting it to trials and errors but also, fundamentally, to see how this endeavour is informed by language itself. ${ }^{20}$

Of course, resorting to inquiry in writing is not entirely new. One needs only turn to Susan Howe's fabulous poetic experiments in history or to Jerome Rothenberg's collections of folkloric songs and poems to realise the importance of inquiry in the structuration of US poetry ${ }^{21}$. However, one cannot but

13 While Laura Poitras installed films, documentation, and archives about mass surveillance and war as part of her project to document post 9/11 America, Attia relied on film interviews he had conducted about phantom limbs.

14 Franck Leibovici/Julien Seroussi, Bogoro. Paris: Questions Théoriques, 2016.

15 Claudia Rankine, Citizen. Minneapolis, MN: Graywolf Press, 2014.

16 See https://graycenter.uchicago.edu/fellowships/the-data-that-we-breathe, date of access: 17 Sept. 2018.

17 Vincent Broqua, Récupérer. Paris: Les Petits Matins, 2015.

18 Marcel Mauss, "Les techniques du corps" (1936), in: Sociologie et anthropologie. Paris: PUF, 1950, pp. 365-386.

19 Lisa Robertson, Occasional Work and Seven Walks from the Office for Soft Architecture. Toronto: Coach House Books, 2003.

20 Lisa Robertson, "Rose," in: Three Summers. Toronto: Coach House Books, 2016, pp. 112-116.

21 For instance, Susan Howe's recent Souls of the Labadie Tract and That this are poetic investigations derived from the history of historical figures and their material relation with 
notice a strong resurgence in the interest for and the practice of inquiry and investigation as a continuation of the experimental project of the 1950s, now with a subject-matter. All of the examples given are not experiments for experiment's sake (if the historical experimenters did that). They are experiments with a twist or with an almost scientific method. And, as we will see with Bergvall's "Say: Parsley" and Osman's Public Figures, the current poetic intervention in the field of research is decidedly one of creating an experience of the experience, and an activation of language.

\section{Bergvall's Investigations into the What and the That of Language}

In "Say: Parsley," Caroline Bergvall investigates the excluding mechanisms of language. How does language skills kill, how are slips of the tongue or puns more than just poetic games? Moreover, how is the experiment with language more than just an aesthetic endeavour? "Say: Parsley" was an installation sited in several different places along the years. ${ }^{22}$ Based on the notion of the shibboleth, the piece was an inquiry in the socially marked pronunciations. It reflected on the fact that because of the mispronunciation of the word perejil, 'parsley' in Spanish, the Creole Haitians were massacred by the Dominicans in 1937. This, as often with Bergvall's bodily as well as research-based writing, ${ }^{23}$ prompted many modes of poetic research from poem to performance to audio-piece. Indeed, her research relied on and gave rise to sound performance, on gestures, on written words on the walls, and on social engagement, particularly through the pronunciation of the letter ' $r$ '24 in English:

In the culturally pluralistic, yet divided, and markedly monolingual society of contemporary Britain, variations in accent and deviations from a broad English pronunciation still frequently entail degrees of

textuality. Jerome Rothenberg's landmark anthology Shaking the Pumpkin is a collection of transcriptions of 'traditional poetry of the Indian North Americas.'

22 For photographs of the installation at the Spacex Gallery and at the Arnolfini Gallery, see http://carolinebergvall.com/work/say-parsley/, date of access: 17 Sept. 2018.

23 Her projects are often thoroughly researched, such as her Meddle English, where her reading and investigations into the origins of English and the literature of Chaucer are theorised politically in 'Middling English,' the practice-based essay that opens the book. Caroline Bergvall, "Middling English," in: Meddle English. New and Selected Texts. Callicoon, NY: Nightboat Books, 2011, pp. 5-19.

24 In a later siting of the same installation, Bergvall used the letter ' $h$ ' as the marker of difference. 
harassment and verbal, sometimes physical, abuse, all according to ethnic and linguistic background. ${ }^{25}$

Among other things, people were asked to say the phrase 'rolling hills.' Suddenly different pronunciations of the same language appeared as if this was a quasi-sociological inquiry. Then the voices were broadcast on loudspeakers in the gallery so that psychoacoustic effects would be created and listeners would have the impression that this language, which was originally English, was either Italian, Hungarian, "hidden or disused first languages resurfaced in this physical and social comprehension game." ${ }^{26}$ From this poetic experiment at the intersection of sociology, linguistics, acoustic science, and poetic practice, a procedural poem emerged which reflected the process of words morphing into others whereby the word 'pig' was gradually and procedurally turned into the word 'parsley.' Later, this poetic piece gave rise to other pieces exploring linguistic foreigning and the experience of one's foreignness. In a later installation in Antwerp based on "Say: Parsley," Bergvall made Dutch speakers listen to the English text of "Say: Parsley" and asked them to write down the words they thought they heard in Dutch. In this homophonic process of acoustic fooling, the notion of the absolute fixity of language was denied, just as another extremely poetic piece was created: a video was made with words projected in Dutch on the wall as the audio file of the English words are read by Bergvall, creating a powerful cross-linguistic investigation. What is remarkable in the writing environments that Bergvall explores is that she treats the that and the what, making sure that the what is being experienced in its full complexity. One of the reasons why this piece qualifies as literary research is that it intertwines research with and through poetic modes.

\section{Jena Osman's Public Figures as a Poetic Activation of Inquiry}

In some ways, poet Jena Osman's Public Figures also does that, but in a different form and with different methods. Public Figures is a poetic essay about our relation to public monuments and a reflection on the writing of this experiment. The book presents itself as an inquiry both practically and theoretically. Indeed, as every investigation, it begins with a question: "How did it occur?" ${ }^{27}$ is the opening sentence, followed by two quotes and an observation

\footnotetext{
25 Bergvall (2005), Parsley, p. 51.

26 Bergvall (2005), Parsley, p. 53.

27 Osman (2012), Public, p. 1.
} 
that form alternative modes of answering this question. The quotes, extracted from Roland Barthes's Camera Lucida and Roy Batty's Blade Runner, address the question of seeing with someone else's eyes. After the initial question, the author presents the object of her practical investigation and a renewed interrogation:

The idea occurred:

Photograph the figurative statues that populate your city. Then bring the camera to their eyes (find a way) and shoot their points of view. What does such a figure see?

To see the sigh of a sighted stone you activate the idea. ${ }^{28}$

As becomes evident here, the exposition of the idea and the method is performatively activated in and by poetic language or by the creation of a specific poiesis. With alliterations in 's' and paronomasias in the last sentence, as if morphing see into sigh into sighted, and stone was part and parcel of the incipient investigation of what seeing means in language ('see the sigh'), as if, to quote Hejinian again, some of the methods were also poetically driven in that they did not avert "suggestions made by language." 29 To be sure, the poem-essay abides by some of the rules of investivation or inquiry: it has a hypothesis, a geographical terrain or field of investigation (Philadelphia), a practical method or protocol described in precise and matter-of-fact language ("you ... jerry-rig an apparatus made from a mop handle, a disposable camera with a timer, some velcro tape. Out in the field, you observe and take notes. You set the timer and pull the pin"), ${ }^{30}$ and it presents the investigation in the shape of a combination of text about and images of the field trip. Some of what might be called the 'results' of this investigation first comes as facing pages: first the photo of one statue is reproduced, then a brief prose text describes and situates the statue historically and geographically, on the facing page, the photo of what the statue 'sees' is reproduced and a text reflects on the nature of what this may mean. For instance, the statue of Major Fulton Reynolds 'looks' on a tree, the text of the facing page says:

Reynolds was very well respected, but his career had few successes. For instance, once after two long days of battle, he fell asleep under a tree and was taken prisoner for six weeks. Was that tree like that tree? Is Reynolds

28 Osman (2012), Public, p. 2.

29 Hejinian (2000), Language, p. 28.

$30 \quad$ Osman (2012), Public, p. 3. 
being forced to look at an emblem of what was perhaps his greatest embarrassment? ${ }^{31}$

Thus described the book is very close to being a regular essay, but Osman also adds smaller fragmentary lines at the bottom of the page, as if they were fine prints, such as "possible new target approaching target one building / designate new target target five pilot copies sensor." These fine prints are transcribed from YouTube videos of drone-pilots in Iraq exchanging with their base. They transform the nature of the book both by inscribing the context of war and updating it to nowadays but also by activating the book further: these tiny couplets create an almost cinematic dimension, as they function like running subtitles, and confer to consecutive pages the illusion that they could be a moving image. This hints towards the process of production, since before Osman published the book the work was presented in the form of a PowerPoint presentation in 2006, and then as a multimedia piece in 2007. ${ }^{32}$ When Osman transferred the multimedia piece into a book, she translated movement by introducing the drone couplets. These lines were totally absent from the preexisting multimedia piece. Moreover, the poiesis of the whole book also activates the language of the inquiry because, as Hejinian says, "poetry takes as its premise that language is a medium for experiencing experience." ${ }^{33}$ Indeed, apart from these transcribed telegraphic exchanges, the poetry is sometimes elliptic, and it sometimes appears in the guise of inconspicuous quasi-maxims such as "You wind up and throw it in the air" or "In the belly, in the clouds, no fixed orbit. You fly a hexagon." ${ }^{34}$ Sometimes it also consists of lineated descriptions of 'images' without the reproductions, as if the literalist ekphrasis was a way to write seeing:

\section{Image:}

The characters are praying before the bayonets.

Rather the ends of the bayonets, the points appearing from out-of-frame as narrow sharks.

Hands clasped at chest, hands clasped before the kneeling boy.

31 Osman (2012), Public, p. 5 .

32 The multimedia piece contains voice, text and animated photographs. It can be viewed on the website of the feminist poetics journal How2 (https://www.asu.edu/pipercwcenter/how2journal/vol_3_no_1/public_figures/, date of access: 17 Sept. 2018). When at the end of her working notes to the piece, Osman says: "this is an ongoing project with much research left to be done," she presents her work explicitly as research (https://www.asu .edu/pipercwcenter/how2journal/vol_3_no_1/public_figures/working.html, date of access: 17 Sept. 2018). 
Hands clasping a robed figure.

Hands open to the sky in a faint.

Hands hiding the eyes.

Hands empty against the floorboards.

Caption: A man with two dogs on leashes. A woman with a small shopping bag. A group of individuals in a line. One cannot look at this. ${ }^{35}$

The description of the so-called 'image' inverts the mode of reading that the book had offered in its first pages. The book thus moves from a display in which you see the picture and then read a prose text as an explanation to a different arrangement in which you read a text and thereby reconstruct a statue. In the latter case, the rhythm created by the text (here with the anaphoras of 'hands') seem to replicate in absentia the possible rhythm of the statue itself. What the reader does, then, is exactly what Osman had called "seeing the sigh of the sighted statue." Moreover, above the 'image' description a so-called 'story' is appended, written in a few lines of prose; and below the description, a so-called 'caption' is added - a shorter poetic prose poem using the mode of everyday notations or lists. With all these devices the investigation is activated by poetry's capacity of allowing one to experience experience. Finally, the book ends on and with poetry: each of the last eight pages contains three couplets, which reproduce the layout (and sometimes the language) of the drone couplets in the previous pages, as well as some of the most intriguing statements in the book that I described as quasi-maxims.

As an essay, the book seeks to show the situatedness of our gaze and how it might matter in times of war. At the same time, as a poem, it shows that in all these findings language matters so much that it creates (poiein) part of the real that one sees or imagines seeing. Poetry is not a beautifying genre here, it is, among other things, one of the tools, or better, the agent used for the inquiry itself. It is what allows the inquiry to find a language. Indeed, Public Figures lays out the what of its inquiry, and spells out its methods, its tools (drawings, arrows, photographs, narrative, quotations ...), as well as the experience of its experience through language. It can, therefore, be considered an example of the brand of literary research that one might call practice-based research.

\section{Conclusion}

To come back to Hejinian's statements that "the reasons and reasonings that motivate poet (and poem) are embedded in the world and in the language 
with which we bring it into view," and that "the resulting praxis is addressed to phenomenological and epistemological concerns," one could posit, in light of Bergvall's and Osman's work, that the contemporary modes of literary research pursue a slightly different approach. For sure, similar as Hejinian conceives it, Bergvall's "Say: Parsley" and Public Figures are inquiries. However, they are specific in that they rely more strongly on documentation, interviews, or idiosyncratic pursuits of quasi-socio-poetic importance. As I have tried to show, if artistic research wishes not to be reified, it needs to open itself up to such hybridisations. But above all, in my opinion, it needs to open itself up to poetry and its powerful linguistic modes of activation of research — and not just to fiction or narrative.

Meanwhile, it does not seem helpful to designate exclusive themes for literary research. To take an extreme example, love, death, and other such traditional themes may be broached by literary artistic research, just like they have been and still are investigated by sociology. Literary research should not be so much concerned with its themes as with its modes and modalities. One of them is the mode of inquiry, which, as I tried to show, it shares with artistic writing. In fact, by describing and exploring the specific mode of inquiry, I wanted to suggest that Bergvall's and Osman's works - today commonly filed under artistic writing - may serve the purpose of complexifying some of the givens of artistic research.

Wesseling claims that "artistic research distinguishes itself from art history by the pivotal role art practice has in the research. Whereas art historians do research into art made by others, artistic research is research in and through art by the artist him- or herself." ${ }^{36}$ Her first sentence will not hold for literary research because poets practice language as much as critics and literary historians do. As practice-based criticism illustrates, the frontiers between regular essays and essay-poems are sometimes not easy to determine. Wesseling's second sentence might be more fruitful for literary research, but here the problem arises that she seems to restrict this type of research to the function of a singular author, namely, "the artist him- or herself." Wesseling is not considering broader and more collective processes of writing, and she is also not considering more hybrid subjectivities, such as a poet that is also a critic (Charles Bernstein or Lyn Hejinian), or a poet that is also an art historian, artist, and a critic (Marjorie Welish). In my opinion, the high level of hybridisation in contemporary practices allows for subtle and supple definitions of literary research, which might be better called literary artistic research. I hope to have shown that literature has a potential as artistic research and that literature must also be 
envisaged within the broader perspective of writing, so that literary research may be regarded as artistic research.

After all, Corina Caduff's question "Why has literature been left out of [the] discourse [of artistic research]?,"37 might be supplemented by another question: why should literature not be envisaged as an art? Indeed, what happens currently in art schools and creative writing departments in universities shows a renewed dialogue between visual or performance arts and literary practices. At the University of Paris 8, where I teach, the MA in écriture littéraire often enrolls students from art schools as well as students from literary studies. The intertwining of artistic practices and literary practices should breed new forms of writers-artists.

\section{Bibliography}

Bergvall, Caroline, "Say: Parsley," in: Fig. Cambridge: Salt Publishing, 2005, pp. 49-6o. Bergvall, Caroline, Meddle English. New and Selected Texts. Callicoon, NY: Nightboat Books, 2011.

Berman, Antoine, L'épreuve de l'étranger. Paris: Éditions Gallimard, 1984.

Broqua, Vincent, Récupérer. Paris: Les Petits Matins, 2015.

Caduff, Corina, "Literature and Artistic Research," in: Corina Caduff et al., eds., Art and Artistic Research. Zurich: Scheidegger \& Spiess, 2010, pp. 12-17.

Denzin, Norman K., "The Reflexive Interview and a Performative Social Science," in: Qualitative Research 1:1 (2001), pp. 23-46.

Formes poétiques contemporaines 9 (2012), Vincent Broqua/Jean-Jacques Poucel, eds. Hejinian, Lyn, The Language of Inquiry. Los Angeles, CA: The University of California Press, 2000.

Howe, Susan, Souls of the Labadie Tract. New York, NY: New Directions, 2007.

Howe, Susan, That This. New York, NY: New Directions, 2010.

Leibovici, Franck/Julien Seroussi, Bogoro. Paris: Questions Théoriques, 2016.

Mauss, Marcel, "Les techniques du corps" (1936), in: Sociologie et anthropologie. Paris: PUF, 1950, pp. 365-386.

Osman, Jena, Public Figures. Middletown, CT: Wesleyan University Press, 2012, also online: https://www.asu.edu/pipercwcenter/how2journal/vol_3_no_1/public_figures/, date of access: 17 Sept. 2018.

Rankine, Claudia, Citizen. Minneapolis, MN: Graywolf Press, 2014.

37 Corina Caduff, "Literature and Artistic Research," in: Corina Caduff et al., eds., Art and Artistic Research. Zurich: Scheidegger \& Spiess, 2010, pp. 12-17: here p. 98. 
Robertson, Lisa, Occasional Work and Seven Walks from the Office for Soft Architecture. Toronto: Coach House Books, 2003.

Robertson, Lisa, "Rose," in: Three Summers. Toronto: Coach House Books, 2016, pp. $112-116$.

Rothenberg, Jerome, Shaking the Pumpkin: Traditional Poetry of the Indian North Americas. Garden City, NY: Doubleday, 1972.

Wesseling, Janneke, Of Sponge, Stone and the Intertwinement with the Here and Now: A Methodology of Artistic Research. Amsterdam: Valiz, 2016. 